Case Reports
in Dermatology
Case Rep Dermatol 2020;12:174-177

DOI: 10.1159/000509179

Published online: October 8, 2020 (c) 2020 The Author(s)

Published by S. Karger AG, Basel www.karger.com/cde

\title{
Omalizumab Use in Chronic Spontaneous Urticaria during Pregnancy and a Four Years' Follow-Up: A Case Report
}

\author{
Laura Michelina Losappio Corrado Mirone Jan Walter Schroeder \\ Joseph Scibilia Luca Balossi Elide Anna Pastorello \\ Unit of Allergology and Immunology, ASST Grande Ospedale Metropolitano Niguarda Ca' \\ Granda, Milan, Italy
}

\section{Keywords}

Urticaria · Pregnancy · Omalizumab

\begin{abstract}
Chronic spontaneous urticaria (CSU) is a benign skin disorder usually responsive to treatment; however, at times it can be difficult to control and become very debilitating. We discuss the case of a woman with CSU that was unresponsive to $\mathrm{H} 1$-antihistamines who was treated with omalizumab and became pregnant during omalizumab treatment. We also considered the follow-up of the mother and newborn for 4 years after delivery. Our case report confirms that omalizumab is a safe and effective therapeutic option, after careful evaluations in terms of cost-effectiveness, in pregnant and lactating women with severe chronic urticaria. Assessment throughout follow-up confirmed a regular progression of pregnancy parameters and no adverse reaction was documented in the child from birth to 4 years of age.
\end{abstract}




\section{Case Reports in Dermatology}

Case Rep Dermatol 2020;12:174-177

DOI: $10.1159 / 000509179$

(c) 2020 The Author(s). Published by S. Karger AG, Basel www.karger.com/cde

Losappio et al.: Omalizumab in Chronic Spontaneous Urticaria

\section{Introduction}

Chronic spontaneous urticaria (CSU) is a benign skin disorder usually responsive to H1antihistamines; however, a fourfold dosage may be required for an adequate urticaria control, as suggested by current guidelines [1]. The off-label H1-antihistamine adjustment may expose the patients to untoward effects of the heart and central nervous system (e.g., QT-interval extension and sedation) $[2,3]$. Moreover, nearly $50 \%$ of the patients need adjunct treatment with corticosteroids or immunosuppressive drugs, both contraindicated in pregnancy. Thus, it may be that in pregnancy omalizumab could be administered as a 3rd line treatment in CSU at the standard dose of $300 \mathrm{mg}$, subcutaneously, every 28 days [4], as indicated in the new Summary of product Characteristic [5]. However, concerns still remain regarding the possible side effects of this drug for the treatment of urticaria during pregnancy because of the limited safety information available especially with respect to the newborn.

Herein, we discuss the case of a woman with CSU that was unresponsive to H1-antihistamines who was treated with omalizumab and became pregnant during omalizumab treatment. We also considered the follow-up of the mother and newborn for 4 years after delivery.

\section{Case Report/Case Presentation}

The patient was a 39-year-old woman affected with severe CSU since 2008. Anamnestic information on her atopy history was negative. She underwent extended diagnostic workup for CSU including blood count, total IgE, serology for infections, autoimmunity, autologous serum skin test. All test results were within normal limits with the exception of Ureaplasma urealyticum in the urine and Helicobacter pylori antigen in the stools; both infections were successfully treated with targeted antibiotics. Total IgE was $871 \mathrm{kU} / \mathrm{L}$. Urticaria severity was assessed by Urticaria Activity Score at 1 (UAS) and 7 days (UAS7), which was 4 and 28, respectively. The patient had undergone treatment with H1-antihistamine (cetirizine up to 10 mg q.i.d.) with unremarkable results. When the CSU had worsened, oral cyclosporine 3 $\mathrm{mg} / \mathrm{kg} /$ day was added to cetirizine for 1 year; however, arterial blood pressure increased above 150/110 mm Hg and the drug was discontinued. Subsequently, severe exacerbation of CSU (5 episodes/year) required short courses of oral prednisone $25 \mathrm{mg} /$ day in addition cetirizine at a maintenance dose of $10 \mathrm{mg}$ /day q.i.d.

When the patient was evaluated at our Center because of a severe urticaria exacerbation (UAS7: 42), omalizumab (300 mg/4 weeks subcutaneously) was initiated, and complete remission of CSU was obtained within 2 weeks (UAS7 $=0$ ); a once monthly dosage of $300 \mathrm{mg}$ maintained a complete remission and no adverse event was reported, such as injection-site reactions, headache, fever, or upper respiratory tract symptoms.

In January 2015, the patient became pregnant, and omalizumab was discontinued for fear of possible adverse effects. The patient subsequently experienced severe worsening of CSU; thus, the possibility of reintroducing omalizumab was considered. The potential risks of omalizumab treatment during pregnancy were explained to the patient (based on the few case reports described in the literature), and informed consent was obtained. Omalizumab was reintroduced at standard monthly dosage, and complete urticaria remission was established. The treatment was maintained for the entire duration of the pregnancy, and in October 2015 the patient gave birth to a healthy male with no congenital abnormalities. The infant was breastfed, and no side effects were observed. 


\section{Case Reports in Dermatology}

Case Rep Dermatol 2020;12:174-177

DOI: $10.1159 / 000509179$

(C) 2020 The Author(s). Published by S. Karger AG, Basel www.karger.com/cde

Losappio et al:: Omalizumab in Chronic Spontaneous Urticaria

Follow-up visits in the subsequent 4 years showed that urticaria was kept in remission with omalizumab. Blood test results were normal, except elevated total IgE $(961 \mathrm{kU} / \mathrm{L})$ in the mother after pregnancy.

The child's serum IgE titer and blood eosinophil count were within normal range, and the child did not present symptoms of allergy or other diseases during the first 4 years of followup. However, the child has recently suffered a single episode of acute urticaria; total IgE were $38 \mathrm{kU} / \mathrm{L}$; specific IgE were negative for wheat, milk, egg yolk, Dermatophagoides farinae, and Dermatophagoides pteronyssinus, and positive for egg-white $(1.78 \mathrm{kU} / \mathrm{L})$; egg was not excluded from the diet and was well tolerated. This case was reported to the official pharmacosurveillance system.

\section{Discussion/Conclusion}

Our case report confirms that omalizumab is a safe and effective therapeutic option, after careful evaluations in terms of cost-effectiveness, in pregnant and lactating women with severe CSU refractory to H1-antihistamines, as already described in previous observational reports [6-9]. Omalizumab, administered at regular monthly doses, maintained urticaria remission without the need for add-on oral steroids.

The good response to omalizumab was promptly restored after a 2-month suspension early in pregnancy.

Despite the fact that omalizumab has been previously associated with preterm birth and thrombocytopenia at birth or within the first month of life [10], we did not detect these clinical conditions. Assessment throughout follow-up confirmed a regular progression of pregnancy parameters, and no adverse reaction was documented in the child from birth to 4 years of age.

Although the Xolair Pregnancy Registry (EXPECT) study on a large population of pregnant women with moderate-to-severe asthma treated with omalizumab did not show evidence of an increased risk of congenital anomalies among the newborns of these patients, as compared to women with asthma treated with conventional drugs [11], a recent study has reported the trans-placental passage of IgG anti-IgE/IgE immune complexes through a neonatal fetal receptor: FcRn [12]. The authors conclude that the placental transport of maternal IgE may modulate the fetal or neonatal immune response.

The detection of egg-specific IgE in our patient's child, even if asymptomatic, warrants clinical follow-up. We therefore recommend monitoring the newborn of women treated with omalizumab during pregnancy, especially in atopic subjects. At present, our case confirms that omalizumab was safe and well tolerated in a pregnant patient with CSU.

\section{Acknowledgement}

The authors would like to thank Springer Healthcare Italia S.r.l. for publication fee assistance. This support was funded by Novartis Farma Italy.

\section{Statement of Ethics}

The patient gave consent for publication. The research was conducted ethically in accordance with the World Medical Association Declaration of Helsinki. 


\section{Case Reports in Dermatology}

\section{Conflict of Interest Statement}

The authors have no conflicts of interest to declare.

\section{Funding Sources}

Novartis Farma Italy.

\section{Author Contributions}

L.M. Losappio treated the patient and wrote the case report, C. Mirone evaluted the data, J.W. Schroeder performed the visits and treated the patient, J. Scibilia wrote the case report, Luca Balossi treated the patient, and E.A. Pastorello visited the patient and wrote the case report.

\section{References}

1 Zuberbier T, Aberer W, Asero R, Abdul Latiff AH, Baker D, Ballmer-Weber B, et al. The EAACI/GA(2) LEN/EDF/WAO guideline for the definition, classification, diagnosis, and management of urticaria. Allergy. 2018;73(7):1393-414.

2 Powell RJ, Leech SC, Till S, Huber PA, Nasser SM, Clark AT; British Society for Allergy and Clinical Immunology. BSACI guideline for the management of chronic urticaria and angioedema. Clin Exp Allergy. 2015 Mar;45(3):547-65.

3 Maurer M, Rosén K, Hsieh HJ, Saini S, Grattan C, Gimenéz-Arnau A, et al. Omalizumab for the treatment of chronic idiopathic or spontaneous urticaria. N Engl J Med. 2013 Mar;368(10):924-35.

4 Kaplan A, Ledford D, Ashby M, Canvin J, Zazzali JL, Conner E, et al. Omalizumab in patients with symptomatic chronic idiopathic/spontaneous urticaria despite standard combination therapy. J Allergy Clin Immunol. 2013 Jul;132(1):101-9.

5 http://www.ema.europa.eu

6 Saini SS, Bindslev-Jensen C, Maurer M, Grob JJ, Bülbül Baskan E, Bradley MS, et al. Efficacy and safety of Omalizumab in patients with chronic idiopathic/spontaneous urticaria who remain symptomatic on H1antihistamines: a randomized, placebo-controlled study. J Invest Dermatol. 2015 Mar;135(3):925.

7 Labrador-Horrillo M, Ferrer M. Profile of omalizumab in the treatment of chronic spontaneous urticaria. Drug Des Devel Ther. 2015 Aug;9:4909-15.

8 González-Medina M, Curto-Barredo L, Labrador-Horrillo M, Giménez-Arnau A. Omalizumab use during pregnancy for chronic spontaneous urticaria (CSU): report of two cases. J Eur Acad Dermatol Venereol. 2017 May;31(5):e245-6.

9 Namazy J, Cabana MD, Scheuerle AE, Thorp JM Jr, Chen H, Carrigan G, et al. The Xolair Pregnancy Registry (EXPECT): the safety of omalizumab use during pregnancy. J Allergy Clin Immunol. 2015 Feb;135(2):407-12.

10 Levi-Schaffer F, Mankuta D. Omalizumab safety in pregnancy. J Allergy Clin Immunol. 2020 Feb;145(2):4813.

11 Namazy JA, Blais L, Andrews EB, Scheuerle AE, Cabana MD, Thorp JM, et al. Pregnancy outcomes in the Omalizumab pregnancy registry and a disease-matched comparator cohort. J Allergy Clin Immunol. 2020 Feb;145(2):528-536.e1.

12 Bundhoo A, Paveglio S, Rafti E, Dhongade A, Blumberg RS, Matson AP. Evidence that FcRn mediates the transplacental passage of maternal IgE in the form of IgG anti-IgE/IgE immune complexes. Clin Exp Allergy. 2015 Jun;45(6):1085-98. 